\title{
The Optical Properties of Greater Florida Bay: Implications for Seagrass Abundance
}

Meredith L. McPherson, Victoria J. Hill, Richard C. Zimmerman \& Heidi M. Dierssen

\section{Estuaries and Coasts}

Journal of the Coastal and

Estuarine Research Federation

ISSN 1559-2723

Estuaries and Coasts

DOI 10.1007/

s12237-011-9411-9
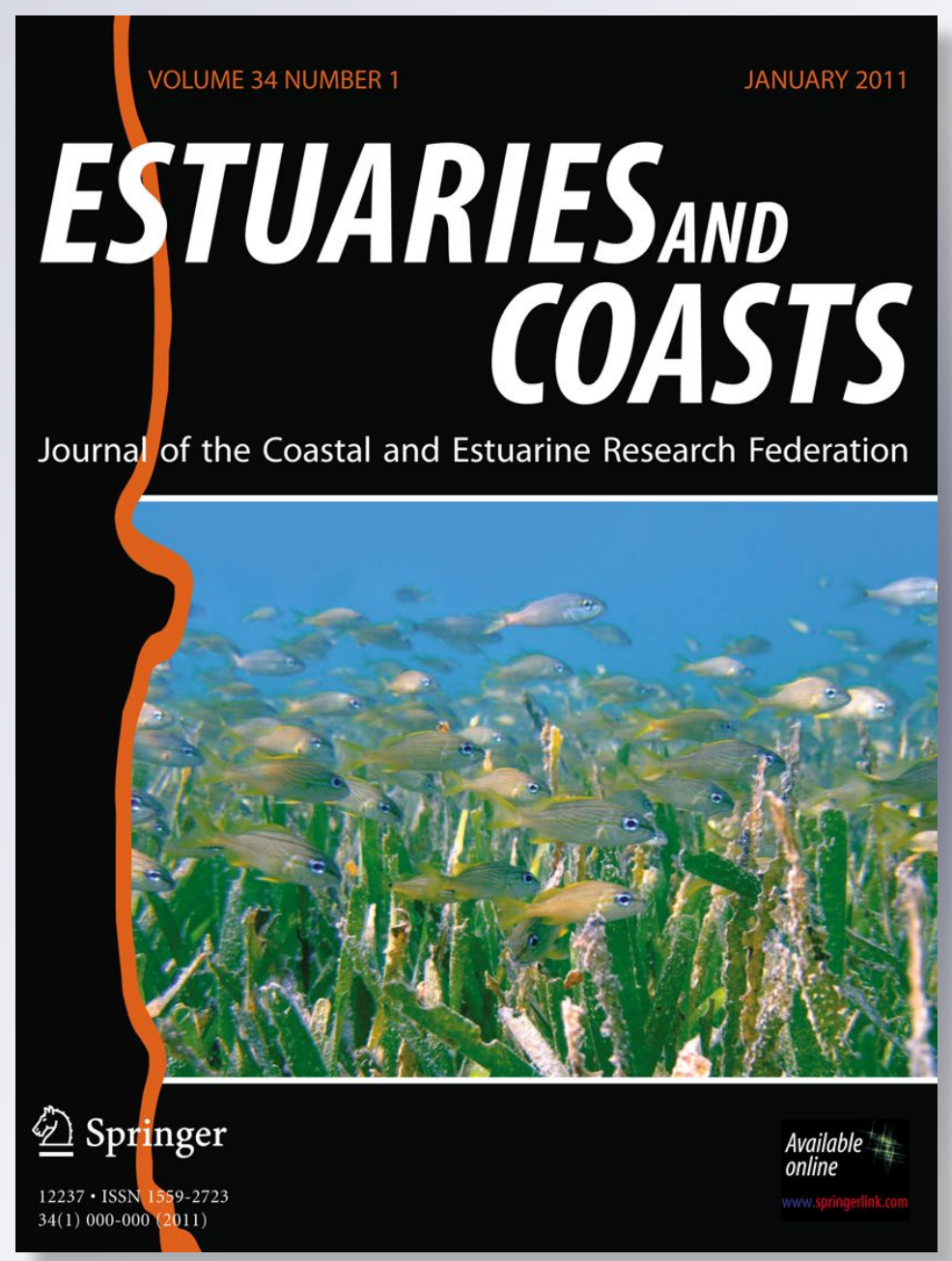

\section{望 Springer}


Your article is protected by copyright and all rights are held exclusively by Coastal and Estuarine Research Federation. This e-offprint is for personal use only and shall not be selfarchived in electronic repositories. If you wish to self-archive your work, please use the accepted author's version for posting to your own website or your institution's repository. You may further deposit the accepted author's version on a funder's repository at a funder's request, provided it is not made publicly available until 12 months after publication. 


\title{
The Optical Properties of Greater Florida Bay: Implications for Seagrass Abundance
}

\author{
Meredith L. McPherson • Victoria J. Hill • \\ Richard C. Zimmerman • Heidi M. Dierssen
}

Received: 19 August 2010 /Revised: 5 April 2011 /Accepted: 6 May 2011

(C) Coastal and Estuarine Research Federation 2011

\begin{abstract}
Water column optical properties of Greater Florida Bay were investigated in the context of their impacts on seagrass distribution. Scattering played an important role in light attenuation throughout the shallow water system. The northwest region was characterized by an absence of seagrasses and the highest scattering by particles, mostly from resuspended carbonate sediments. Higher seagrass densities were observed in the open waters just north of the Florida Keys, where absorption coefficients were dominated by colored dissolved organic material and scattering was lower than in the northwest region. Patchy dense seagrass meadows were observed in the clear waters south of the Keys where scattering and absorption were low and contributed equally to light attenuation. In general, seagrasses were observed in areas where $>7.5 \%$ of surface irradiance reached the plants and where optical properties were not dominated by scattering. Although the prevention of eutrophication and
\end{abstract}

Electronic supplementary material The online version of this article (doi:10.1007/s12237-011-9411-9) contains supplementary material, which is available to authorized users.

M. L. McPherson $(\bowtie) \cdot$ V. J. Hill $\cdot$ R. C. Zimmerman

Department Ocean, Earth and Atmospheric Sciences,

Old Dominion University,

4600 Elkhorn Avenue,

Norfolk, VA 23529, USA

e-mail:mmcph005@gmail.com

V. J. Hill

e-mail: vhill@odu.edu

R. C. Zimmerman

e-mail: rzimmerm@odu.edu

H. M. Dierssen

Department of Marine Sciences, University of Connecticut,

1080 Shennecossett Road,

Groton, CT 06340-6048, USA

e-mail: heidi.dierssen@uconn.edu nuisance algal blooms may be necessary for preserving seagrass meadows in this system, our observations and model calculations indicate that nutrient control alone may be insufficient to permit seagrass recolonization if optical properties are dominated by particulate scattering from resuspended sediments.

Keywords Seagrass · Optical properties · Florida Bay · Scattering $\cdot$ Light

\section{Introduction}

Optical characteristics of shallow coastal and estuarine environments, such as Florida Bay, differ substantially from those of the open ocean. Inherent optical properties of the open ocean are determined predominantly by phytoplankton and their degradation products (case 1; Morel and Prieur 1977). In contrast, the optical properties of most coastal marine environments, or "case 2" waters, are influenced by significant amounts of terrestrially derived colored dissolved organic material (CDOM), detritus, and suspended sediment, in addition to phytoplankton (Kirk 1994; Prieur and Sathyendranath 1981). These optically complex regions can present significant challenges for retrieving optical properties from remote sensing algorithms and for characterizing the quantity and quality of light available to benthic primary producers.

The spectral characteristics of light incident on the leaves of submerged plants depend on the inherent (IOPs) and apparent optical properties (AOPs) of the water column. The IOPs of absorption and scattering, in turn, depend on the concentration and nature of particulate and dissolved compounds in the water column. The AOPs, such as diffuse attenuation, depend on the angular distribution of light within 
the water column influenced by sun angle, as well as the IOPs. Phytoplankton, non-algal detritus, minerals, and CDOM absorb strongly in the blue region of the visible spectrum. Suspended sediments (particularly carbonate) strongly scatter light, increasing photon path length and diffuse attenuation (Dierssen et al. 2010; Kirk 1994). Thus, suspended and dissolved components of the water column preferentially scavenge blue light (an efficient driver of photosynthesis) from the water column (Morel 1978; Zimmerman 2006).

The abundance and distribution of seagrasses in Florida Bay declined by approximately $30 \%$ from 1,760 to $1,232 \mathrm{~km}^{2}$ throughout the 1980s and 1990s (Stumpf et al. 1999). Everglades National Park is believed to have sustained the greatest losses, estimated at $270 \mathrm{~km}^{2}$ or $51 \%$ of the total regional loss (Zieman 1982; Zieman et al. 1989). Seagrass die-offs outside the park boundary $\left(400 \mathrm{~km}^{2}\right)$ were poorly documented but approximated $<50 \%$ of the total loss (Zieman 1982). The reduction of seagrass has been attributed to many environmental factors, including disease, high respiratory demand, eutrophication (Hall et al. 1999), high salinity, increased temperatures, light availability, and sulfide toxicity (Borum et al. 2005; US Fish and Wildlife Service 1999). A consensus on the primary cause has never been ascertained (Boesch et al. 1993; Hall et al. 1999)

Florida Bay and regions to the west, including "Greater Florida Bay", represent a complex ecosystem influenced by numerous environmental factors and interlinked biogeochemical and ecological processes. Seagrass declines in Everglades National Park and Greater Florida Bay were accompanied by a cascade of ecological changes, including (a) considerable reductions in water transparency resulting from increased phytoplankton abundance and particulate turbidity (Durako et al. 2007), (b) declines in fish and invertebrate populations (Butler et al. 1995), and (c) blooms of nuisance macroalgae capable of smothering seagrasses and corals (Zieman et al. 1989). Although the chain of events responsible for initiating the mass die-off of seagrass are still not fully understood, these submerged angiosperms have notoriously high light requirements, and water quality deterioration resulting in light limitation is a leading cause of their decline throughout the world (Duarte 1991; Ralph et al. 2007).

Historically, the shallow subtidal environment of Florida Bay, including Greater Florida Bay, provided ideal conditions for survival and proliferation of dense seagrass meadows. Despite tremendous losses suffered in the past 30 years, South Florida still supports roughly $55-65 \%$ of Florida's seagrass resources (Carlson and Madley 2007; Sargent et al. 1995) and the greatest population densities on the state's coastline. There is also evidence of recent recovery among Thalassia testudinum populations in southern Greater Florida Bay and on the southern side of Long Key within Florida Keys National Marine Sanctuary (Fourqurean 2008).
Seagrass meadows throughout Florida Bay are variously populated by four species: T. testudinum, Halodule wrightii, Syringodium filiforme (Hall et al. 1999), and Halophila engelmannii (Carlson and Madley 2007; Fourqurean et al. 2003), of which $T$. testudinum was primarily affected by historic die-offs. The northern region of Greater Florida Bay is extremely turbid due to sediment resuspension (Kelble et al. 2005; Stumpf et al. 1999). Fourqurean et al. (2001, 2003) reported the presence of $H$. wrightii and Halophila in this area, but T. testudinum and S. filiforme have not colonized the highly turbid areas and persistent seagrass loses throughout the 1990s were attributed to decreasing water quality and light availability (Hall et al. 1999).

This study investigated the relationships between water column optical properties and spectral light attenuation and modeled their impacts on the distribution and abundance of seagrasses along the Florida Keys and Greater Florida Bay. By characterizing the optical impacts of dissolved and suspended constituents on the submarine light environment, this study provides insight into environmental factors relevant to present and future distributions of seagrasses in Greater Florida Bay.

\section{Materials and Methods}

\section{Study Site}

Water column optical properties and seagrass abundances were measured at 15 stations in Greater Florida Bay, an area just west and south of the Everglades National Park, from 27 June to 5 July 2005 and 19 June to 3 July 2006 (Fig. 1a, b). The western boundary of the study site was defined by the $81^{\circ} 08^{\prime} \mathrm{W}$ meridian and the eastern boundary by the Everglades National Park. Stations occupied in 2005, but not 2006, included those stations running northwest to Cape Sable (Fig. 1a, b, region A). Reef stations on the oceanic side of the Florida Keys were occupied in both years for comparison to Florida Bay (Fig. 1a, b, region C). Depths ranged from $2 \mathrm{~m}$ inside the bay (north of the Florida Keys) to $17 \mathrm{~m}$ at the reef sites (south of the Florida Keys). The water column was vertically homogeneous (unstratified) from the surface to the sea floor at all station.

\section{Seagrass Measurements}

Seagrass Abundance Densities of T. testudinum, $H$. wrightii, and S. filiforme were measured by counting all shoots within 25 to 50 randomly located quadrats $\left(0.04 \mathrm{~m}^{2}\right)$ at each station. Representative shoots were harvested from each quadrat for determination of leaf morphologies in the laboratory according to Zimmerman (2003). Lengths of all 


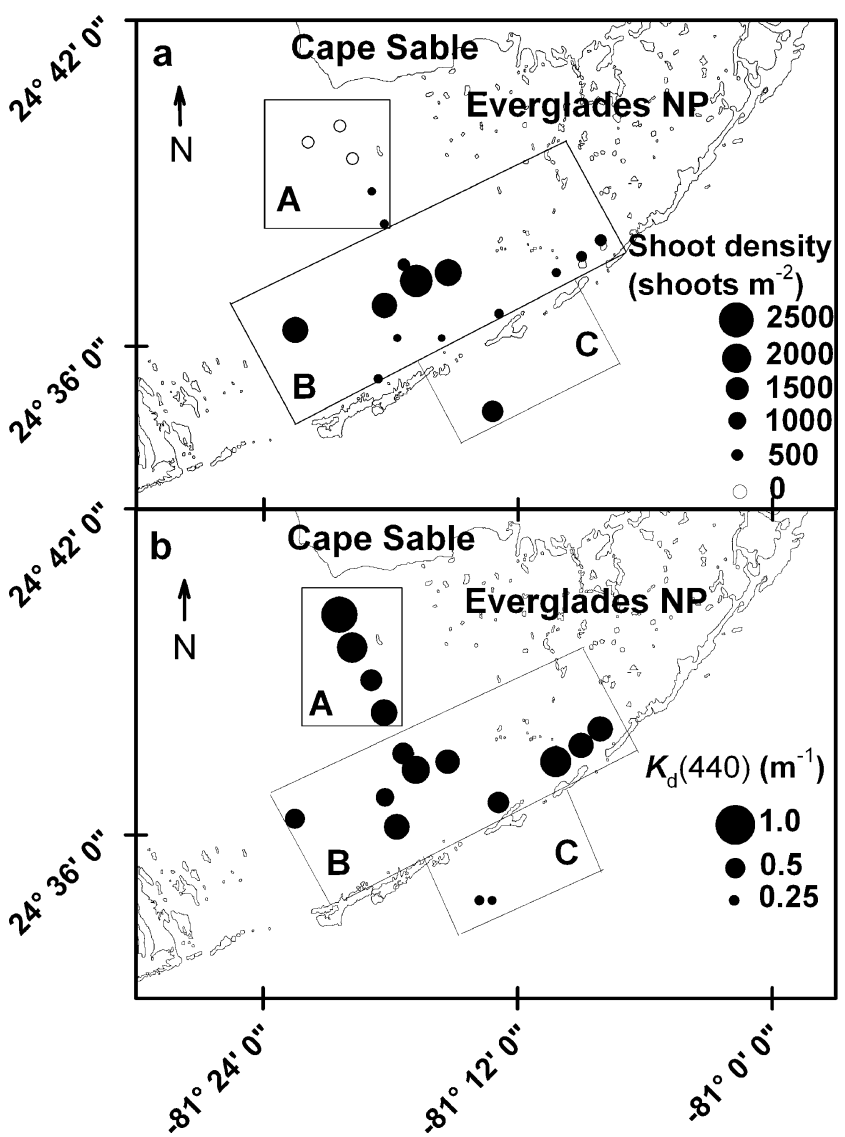

Fig. 1 a Measured seagrass abundances for stations in Greater Florida Bay occupied during the summers of 2005 and 2006 and divided into three regions: A, B, and C. Symbol size is proportional to shoot density. b Magnitude of diffuse attenuation coefficient at $440 \mathrm{~nm}$ $\left[K_{\mathrm{d}}(440)\right]$ for stations in Greater Florida Bay occupied during the summers of 2005 and 2006 and divided into three regions: A, B, and C. Symbol size is proportional to $K_{\mathrm{d}}(440)$

leaves on the collected shoots were measured to the nearest $\mathrm{mm}$ using a flexible tape measure and summed to determine total leaf length for each shoot. Leaf widths were measured to the nearest $0.1 \mathrm{~mm}$ using a digital caliper. The total onesided leaf area for each shoot $\left(\mathrm{m}^{2}\right.$ shoot $\left.^{-1}\right)$ was calculated as the product of total leaf length and leaf width. Leaf area indices (LAI) were calculated for each station as the product of shoot density (shoots $\mathrm{m}^{-2}$ ) and shoot leaf area $\left(\mathrm{m}^{2} \operatorname{shoot}^{-1}\right)$.

\section{In Water Optical Measurements}

To minimize confusion and to adhere to the increasingly popular conventions emerging from the field of hydrologic optics, the symbols and definitions used here (Table 1) will conform to those of Kirk (1994) and Mobley (1994). These observations are from summer months and may not represent the full range of optical properties from the region; however, our observations are fairly consistent with the more temporally extensive set of optical property data published by Kelble et al. (2005), suggesting that they are representative of a relevant climatological mean for the purposes intended here.

Additionally, several wavelength specific analyses are presented in the results. Optical measurements were performed across the visible spectrum (400 to $700 \mathrm{~nm}$ ) with varying degrees of resolution depending on the instrument. Results for specific wavelengths presented here were selected to be representative of the overall trends seen across the spectra. Although absorption by suspended and dissolved water column components is greatest in the blue (400 to $488 \mathrm{~nm}$ ), scattering (corrected for absorption) is relatively independent of wavelength.

Inherent Optical Properties Suspended particles were collected at each station by filtering surface water samples (400 to $640 \mathrm{~mL}$, depending on particle density) onto Whatman GF/F filters. Low vacuum pressure was maintained to prevent breakage of living cells. Spectral absorption of the particulate $\left[a_{\mathrm{p}}(\lambda)\right]$ fraction captured on the filters was measured across the visible and near-IR spectrum (400-1,800 nm, $1 \mathrm{~nm}$ resolution) using a FieldSpec Pro spectrophotometer (Analytical Spectral Devices, Inc.) fitted with an integrating sphere in accordance with current NASA protocols (Mitchell et al. 2002). A filter pad moistened with Nanopure ${ }^{\circledR}$ water functioned as

Table 1 Summary of symbols, their definitions, and dimensions

\begin{tabular}{|c|c|c|}
\hline Symbol & Definition & Dimensions \\
\hline \multicolumn{3}{|c|}{ Basic parameters } \\
\hline$z$ & Depth of water column & $\mathrm{m}$ \\
\hline TSM & Total suspended material & $\mathrm{mg} \mathrm{L}^{-1}$ \\
\hline LAI & Leaf area index & $\mathrm{m}^{2} \mathrm{~m}^{-2}$ \\
\hline \multicolumn{3}{|c|}{ Inherent optical properties of the water column } \\
\hline$a_{\mathrm{p}}$ & $\begin{array}{l}\text { Absorption by particulate material, } \\
\text { algal }+ \text { sediment }+ \text { detritus }\end{array}$ & $\mathrm{m}^{-1}$ \\
\hline$a_{\mathrm{g}}$ & Absorption by CDOM & $\mathrm{m}^{-1}$ \\
\hline$a_{\mathrm{pg}}$ & Absorption by particulate and CDOM & $\mathrm{m}^{-1}$ \\
\hline$a_{\mathrm{w}}$ & Absorption by pure water & $\mathrm{m}^{-1}$ \\
\hline$a_{\mathrm{t}}$ & Total absorption (includes water) & $\mathrm{m}^{-1}$ \\
\hline$b_{\mathrm{p}}$ & Scattering by particulate material & $\mathrm{m}^{-1}$ \\
\hline$b_{\mathrm{bp}}$ & Backscattering by particulate material & $\mathrm{m}^{-1}$ \\
\hline$b_{\mathrm{bp}} / b_{\mathrm{p}}$ & Ratio of backscattering to total scattering & Dimensionless \\
\hline$c_{\mathrm{pg}}$ & Beam attenuation coefficient & $\mathrm{m}^{-1}$ \\
\hline \multicolumn{3}{|c|}{ Apparent optical properties of the water column } \\
\hline$K_{\mathrm{d}}(\lambda)$ & $\begin{array}{l}\text { Spectral diffuse water column } \\
\text { attenuation coefficient at } \\
\text { wavelength, } \lambda\end{array}$ & $\mathrm{m}^{-1}$ \\
\hline$\zeta(\lambda)$ & Optical depth $\left[=K_{\mathrm{d}}(\lambda) \cdot z\right]$ & Dimensionless \\
\hline Chl $a$ & Chlorophyll $a$ concentration & $\mu g \mathrm{~L}^{-1}$ \\
\hline
\end{tabular}


a blank. The average absorption from 790 to $800 \mathrm{~nm}$ was then subtracted to correct for residual non-specific scattering (Mitchell et al. 2002). Dissolved material was obtained by collecting water samples passed through $0.2 \mu \mathrm{m}$ polycarbonate filters. Absorption by the dissolved material $\left[a_{\mathrm{g}}(\lambda)\right]$ was measured at the same spectral resolution in a 10 -cm quartz cuvette against a Nanopure ${ }^{\circledR}$ deionized water blank. Total absorption was calculated as:

$a_{\mathrm{t}}(\lambda)=a_{\mathrm{p}}(\lambda)+a_{\mathrm{g}}(\lambda)+a_{\mathrm{w}}(\lambda)$

where spectral absorption coefficients for pure water $\left[a_{\mathrm{w}}(\lambda)\right]$ were taken from Pope and Fry (1997).

Total non-water attenuation $\left(c_{\mathrm{pg}}\right)$ and absorption $\left(a_{\mathrm{pg}}\right)$ were measured at nine wavelengths $(412,440,488,510,532,555$, 650,676 , and $715 \mathrm{~nm} ; 10 \mathrm{~nm}$ bandwidth) using an $a c-9$ Plus system (WET Labs, Inc.) deployed from the boat at each station. The instrument was flushed and allowed to warm up for $2 \mathrm{~min}$ before each recording. Data were processed and corrected for ambient temperature, salinity, and scattering (methods 1 and 3) in accordance with Section 5 of the WET Labs $a c$ Meter Protocol Document (WET Labs 2009). Total scattering by particulate material $\left(b_{\mathrm{p}}\right)$ was calculated as taking the difference between $c_{\mathrm{pg}}$ and $a_{\mathrm{pg}}$.

Backscattering $\left(b_{\mathrm{bp}}\right)$ was measured at six wavelengths (412, 488, 510, 550, 676, and $852 \mathrm{~nm})$ using a Hydroscat-6 (HS-6, HOBI Labs, Inc.) optical backscattering instrument deployed alongside the ac-9. Five minutes of data were recorded every $15 \mathrm{~min}$ ( $5 \mathrm{~min}$ on, $10 \mathrm{~min}$ off) for the duration of each station. HS-6 data were corrected for absorption and scattering using $a c-9$ data collected at each site (Mitchell et al. 2002). The backscattering ratio, calculated from $H S-6$ and $a c-9$ data as $\left(\frac{b_{\mathrm{bp}}(550)}{b_{\mathrm{p}}(555)}\right)$, is important for investigating the relative influences of pigmented particles (low backscattering ratio) and non-pigmented particles (high backscattering ratio) on the light field (Twardowski et al. 2001). The different wavelengths used in this ratio resulted from slight mismatch in the green channels of the $a c-9$ $(555 \mathrm{~nm})$ and $H S-6(550 \mathrm{~nm})$ instruments.

The highly attenuating waters encountered at two stations in region A exceeded the dynamic range for beam attenuation of our $a c-9$ instrument equipped with $25-\mathrm{cm}$-long tubes, causing $c_{\mathrm{pg}}$ to be underestimated by the routine data processing algorithm. Similarly, backscattering $\left(b_{\mathrm{bp}}\right)$ data from the $H S-6$ was influenced by the highly attenuating waters in region A. Total attenuation $\left(c_{\mathrm{pg}}\right)$ and backscattering $\left(b_{\mathrm{bp}}\right)$ data for these two stations were corrected using the relationship against total suspended material (TSM) $<5 \mathrm{mg} \mathrm{L}^{-1}$, determined by linear regression of data from the remaining stations. Total scattering values $\left(b_{\mathrm{p}}\right)$ for these stations were calculated by subtracting total absorption $\left(a_{\mathrm{pg}}\right)$ from the corrected $c_{\mathrm{pg}}$ values (Kirk 1994). All calculations of the backscattering ratio were made using corrected $b_{\mathrm{p}}$ and $b_{\mathrm{bp}}$ values.
Apparent Optical Properties The diffuse attenuation coefficient for downwelling spectral irradiance $\left[K_{\mathrm{d}}(\lambda)\right]$ from 400 to $700 \mathrm{~nm}$ was determined using a HydroRad-4 (HR-4) spectroradiometer system (HOBI Labs, Inc.) fitted with two Gershun irradiance sensors and two plane irradiance sensors. The HR-4 was deployed on the seabed with the two hemispherical Gershun sensors positioned $1 \mathrm{~m}$ above the bottom measuring downwelling $\left[E_{g-\mathrm{dn}}(\lambda)\right]$ and upwelling $\left[E_{\text {g-up }}(\lambda)\right]$ Gershun irradiance (Hojerslev 1975). Total scalar irradiance was calculated as:

$E_{\mathrm{o}}(\lambda)=E_{\mathrm{g}-\mathrm{dn}}(\lambda)+E_{\mathrm{g}-\mathrm{up}}(\lambda)$

The plane irradiance sensors (labeled $E_{\mathrm{d} 1}$ and $E_{\mathrm{d} 2}$ ) were positioned on the frame to avoid instrument shading and measure downwelling irradiance separated by a vertical distance of $1 \mathrm{~m}$. The native spectral distribution is unique for each channel of this instrument (nominally $0.3 \mathrm{~nm}$ ), and the raw spectra were resampled to a uniform resolution and wavelength increment of $1 \mathrm{~nm}$ using a cubic spline. The attenuation coefficient for downwelling plane irradiance $\left[K_{\mathrm{d}}(\lambda)\right]$ was then calculated from the resampled spectra $(1 \mathrm{~nm}$ resolution) as:

$K_{\mathrm{d}}(\lambda)=\frac{-\ln \frac{E_{\mathrm{d1}}(\lambda)}{E_{\mathrm{d} 2}(\lambda)}}{z}$

where $z=1 \mathrm{~m}$.

\section{Total Suspended Material and Carbonate Content}

Suspended material from surface water samples $(\sim 100$ to $1,000 \mathrm{~mL}$ ) was collected onto pre-weighed Whatman Nuclepore Track-Etch ${ }^{\circledR}$ Membrane filters (nominal pore size $0.8 \mu \mathrm{m}$ ) under gentle vacuum and rinsed with deionized water to remove residual salts. The filters were dried at $90^{\circ} \mathrm{C}$ for approximately 5 days and then weighed on an analytical balance to a precision of $10 \mu \mathrm{g}$. The mass of each sample was calculated by subtracting the mass of clean filter from the total mass. The concentration of TSM (milligrams per liter) was calculated as the ratio of sample mass to volume filtered.

The contribution of carbonate sediment to TSM for regions $\mathrm{B}$ and $\mathrm{C}$ was determined by loss of weight upon dissolution in dilute acid. Approximately $5 \mathrm{~mL}$ of $5 \% \mathrm{HCl}$ was gravity fed through the dried filters, washed with $10 \mathrm{~mL}$ Nanopure ${ }^{\circledR}$ deionized water to remove all remaining salts, and dried for 1 day at $90^{\circ} \mathrm{C}$. Final mass of each sample excluding carbonate sediment was measured to a precision of $10 \mu \mathrm{g}$ and subtracted from the total dry mass to calculate the amount of carbonate sediment suspended in the water column at each sample area. Data for region A were unavailable for inclusion into the data analysis. 
Modeling Light-Limited Seagrass Density

Light-limited seagrass density at each station was determined from daily carbon balance estimates using the twoflow radiative transfer model developed for Zostera marina and T. testudinum by Zimmerman (2001, 2003, 2006) and modified for S. filiforme by Stoughton (2008). The model consisted of three separate modules that (a) simulated the architecture, including leaf geometry, of the seagrass canopy and leaf and water column optical properties, (b) calculated the vertical spectral irradiance distribution within the submerged leaf canopy, and (c) calculated the seagrass photosynthesis that resulted from spectral light absorption by the leaves. Station-specific values for canopy architecture, leaf orientation, and leaf and water column IOPs (described above) were used to initialize the model for each calculation. Daily seagrass productivity, driven by the photosynthetically utilized radiation (PUR) captured by the leaves, was calculated by the model assuming the daily variation in irradiance was sinusoidal. The photoperiod for these calculations was set to $12 \mathrm{~h}$ (i.e., equinox), assuming that excess summertime production was symmetrical with the winter deficit. The maximum light-limited density for each station was determined by the density at which daily photosynthesis $(12 \mathrm{~h})$ of the shoot was equal to the daily ( $24 \mathrm{~h}$ ) respiratory demand of the entire plant, including the below-ground roots and rhizomes.

The hypothetical influences of changes in CDOM and Chl $a$ concentrations on the predicted light-limited densities were explored using spectral diffuse attenuation coefficients $\left[K_{\mathrm{d}}(\lambda)\right]$ modeled for a range of CDOM absorption and Chl $a$ concentrations (two, five, ten, and 15 times measured values) using Hydrolight ${ }^{\mathbb{B}}$ 5.0 (Mobley 1989; Mobley 1994). Proper simulation of Chl $a$ required separate amplification of $a$ and $b$ prior to input into Hydrolight $t^{\mathbb{B}}$ since phytoplankton affect scattering and absorption disproportionately. It was assumed that CDOM influenced absorption but not scattering coefficients. The resulting $K_{\mathrm{d}}(\lambda)$ values generated by Hydrolight ${ }^{\circledR}$ were then used to determine daily carbon balance estimates and light-limited shoot densities using the two-flow radiative transfer model described above Zimmerman (2003).

\section{Results}

Light Absorption and Attenuation

The study area was segregated into three regions based on differences in shoot density and light attenuation $\left[K_{\mathrm{d}}(440)\right]$ (Fig. 1a, b). Seagrasses were absent from three of the five stations in region $\mathrm{A}$, and shoot density was below 200 shoots $\mathrm{m}^{-2}$ for the remaining two stations (Fig. 1a).
In addition to vanishingly low shoot densities, region A was characterized by the highest average values of $K_{\mathrm{d}}(\lambda)$ (Figs. 1b and 2). Seagrasses were present at all stations in region $\mathrm{B}$ at densities ranging from 70 to 2,500 shoots $\mathrm{m}^{-2}$ (Fig. 1a). Seagrass densities were lower (70 to 451 shoots $\mathrm{m}^{-2}$ ) near the Florida Keys than in more open waters to the north $\left(>2,000\right.$ shoots $\left.\mathrm{m}^{-2}\right)$. Region B was characterized by mean $K_{\mathrm{d}}(\lambda)$ values that were significantly lower than region A (ANOVA; Table 2). In the clear oceanic waters (region C) southeast of the Keys, seagrass meadows were present at densities between 145 and 1,250 shoots $\mathrm{m}^{-2}$ (Fig. 1a) and $K_{\mathrm{d}}(\lambda)$ values were significantly lower than both regions A and B (Gould Jr. et al. 1999; Electronic Supplemental Material Table 1).

Spectral differences in mean $K_{\mathrm{d}}(\lambda)$ and total spectral absorption $a_{\mathrm{t}}(\lambda)$ among regions were most apparent in the blue (Fig. 2a). The mean total absorption spectra without water $\left(a_{\mathrm{pg}}\right)$ for regions $\mathrm{A}$ and $\mathrm{B}$ were similar in both shape and magnitude across the visible spectrum. For regions $\mathrm{A}$ and $\mathrm{B}$, both mean $a_{\mathrm{t}}(\lambda)$ and $K_{\mathrm{d}}(\lambda)$ were greatest at blue $(400$ to $450 \mathrm{~nm})$ and red $(600$ to $700 \mathrm{~nm})$ wavelengths. In region $\mathrm{C}, a_{\mathrm{t}}(\lambda)$ and $K_{\mathrm{d}}(\lambda)$ were spectrally flat between 400 and $550 \mathrm{~nm}$ only increasing in the red and near-infrared. The low variance in $a_{\mathrm{t}}(\lambda)$ indicates that high variance in $K_{\mathrm{d}}(\lambda)$ was driven by the variations in scattering properties that control backscattering $\left(b_{\mathrm{b}}\right)$ and the average cosine $(\bar{\mu})$, since $K_{\mathrm{d}}$ scales as $\frac{a+b_{\mathrm{b}}}{\bar{\mu}}$. In contrast, the variances in $K_{\mathrm{d}}(\lambda)$ were consistently lower in regions $B$ and $C$, suggesting much less variance in scattering across the regions that supported much higher seagrass densities.

Absorption by particulate $\left(a_{\mathrm{p}}\right)$ and dissolved $\left(a_{\mathrm{g}}\right)$ material contributed equally to total absorption $\left(a_{\mathrm{t}}=a_{\mathrm{p}}+a_{\mathrm{g}}+a_{\mathrm{w}}\right)$ in the blue and green regions of the spectrum in region $\mathrm{A}$ (Fig. 2b). In comparison, $a_{\mathrm{g}}$ was responsible for $75 \%$ of the total absorption in region $\mathrm{B}$. Total absorption in the blue and green measured in region $\mathrm{C}$ was approximately $10 \%$ of that in regions $\mathrm{A}$ and B. Contributions by $a_{\mathrm{p}}$ and $a_{\mathrm{g}}$ were equal across the blue region of the spectrum in region $\mathrm{C}$, but absorption by water $\left(a_{\mathrm{w}}\right)$ drove spectral characteristics of the water column beyond $550 \mathrm{~nm}$. Likewise, water was the most important driver of total absorption in the red across all three regions. The dissolved component of absorption was responsible for less than $60 \%$ of $a_{\mathrm{pg}}(440)$ in the highly turbid and variable scattering environment of region $\mathrm{A}$ (Fig. 3a). Absorption by CDOM was the primary driver of $a_{\mathrm{pg}}$ in region $\mathrm{B}$, as it represented more than $60 \%$ of $a_{\mathrm{pg}}(440)$ at all stations across this region. Particles and CDOM contributed equally to the low values of $a_{\mathrm{pg}}(440)$ $\left(<0.1 \mathrm{~m}^{-1}\right)$ observed in region $\mathrm{C}$. With the exclusion of one outlier, the relationship between $a_{\mathrm{pg}}$ and $\% a_{\mathrm{g}}$ in region $\mathrm{B}$ was linear and significantly higher $(p<0.05)$ than in region A (Fig. 3a). 
Fig. 2 a Average spectral downwelling attenuation $\left[K_{\mathrm{d}}(\lambda)\right]$ and total water column absorption $\left[a_{\mathrm{t}}(\lambda)\right]$ for stations from regions $\mathrm{A}, \mathrm{B}$, and $\mathrm{C}$. Dashed lines represent total absorption. Eight discrete wavelengths analogous with the $a c-9$ include \pm 1 standard error. Shaded areas represent \pm 1 standard error of mean $K_{\mathrm{d}}(\lambda)$ values. b Cumulative absorption plots for each region which included $a_{\mathrm{p}}$ (solid gray), $a_{\mathrm{p}}+a_{\mathrm{g}}$ (left-leaning diagonal lines), and $a_{\mathrm{t}}$ (cross-hatched). The $y$-axis label is shown on the right-hand side

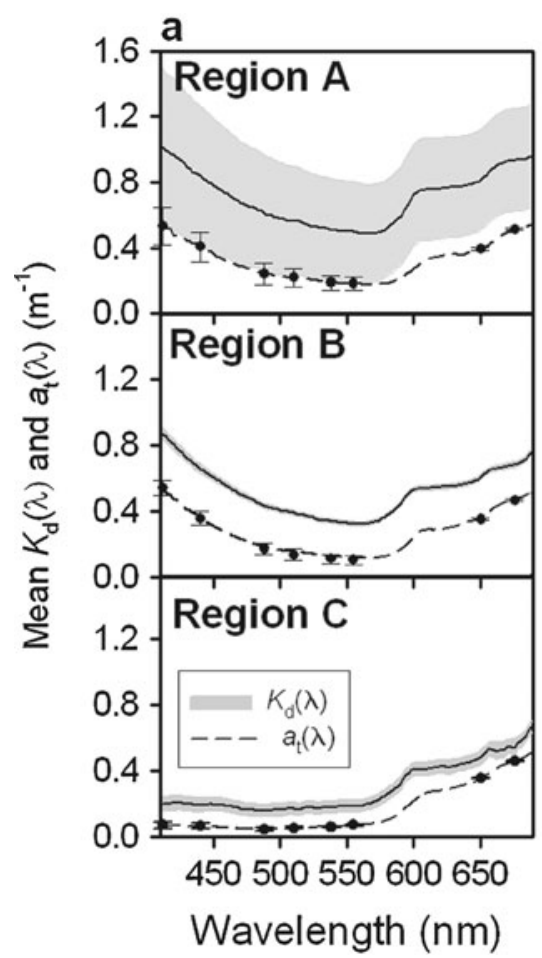

\section{Scattering}

The relationship between particulate scattering $\left[b_{\mathrm{p}}(440)\right]$ and absorption by particulate and dissolved material $\left[a_{\mathrm{pg}}(440)\right]$ was strongly linear $\left(r^{2}=0.92\right)$ across regions A and C (Fig. 3b). This same relationship was not statistically significant $(p>0.05)$ in region B because of the strong influence of absorption by CDOM, which does not contribute to scattering. Scattering was greater in region $\mathrm{A}$ [mean $b_{\mathrm{p}}(440)=3.42 \pm 0.37$ ] than regions $\mathrm{B}$ [mean $\left.b_{\mathrm{p}}(440)=1.12 \pm 0.14\right]$ and $\mathrm{C}\left[\right.$ mean $b_{\mathrm{p}}(440)=0.22 \pm$ 0.071] (Electronic Supplemental Material Table 2). In addition to exhibiting the highest $b_{\mathrm{p}}(440)$, the backscattering ratio $\left(b_{\mathrm{bp}} / b_{\mathrm{p}}\right)$ of region $\mathrm{A}$ was higher than for regions $\mathrm{B}$ and C (Table 2, Electronic Supplemental Material 3b) which were not significantly different from each other (Electronic Supplemental Material Tables 2b and 3b). An

Table 2 Mean backscattering to scattering fraction $\left[b_{\mathrm{bp}}(550) /\right.$ $\left.b_{\mathrm{p}}(555)\right]$, by region, \pm 1 standard error

\begin{tabular}{lll}
\hline Year & Region & Mean $b_{\mathrm{bp}} / b_{\mathrm{p}}$ \\
\hline 2005 & $\mathrm{~A}$ & $0.032 \pm 0.003$ \\
& $\mathrm{~B}$ & $0.028 \pm 0.001$ \\
& $\mathrm{C}$ & $0.022 \pm 0.008$ \\
2006 & $\mathrm{~B}$ & $0.020 \pm 0.001$ \\
& $\mathrm{C}$ & $0.011 \pm 0.000$ \\
\hline
\end{tabular}

invariant particulate composition should yield a backscattering ratio that is constant and independent of $b_{\mathrm{p}}$. However, the backscattering ratio increased nonlinearly to a constant value in response to $b_{\mathrm{p}}$ (Fig. 4). This trend suggests a shift in particulate composition from organic (low $b_{\mathrm{bp}}$ ) to mineral (high $b_{\mathrm{bp}}$ ) material as $b_{\mathrm{p}}$ increased.

Although $\mathrm{Chl} a$ concentrations were generally below $3 \mu \mathrm{g} \mathrm{L}^{-1}$ during our study, a significant positive relationship between $\mathrm{Chl} a$ and particulate backscattering $\left[b_{\mathrm{bp}}(550)\right]$ was observed across all three regions $(p<0.05$, Fig. 5). Chl a concentrations, however, did not control characteristics of backscattering within the individual regions of $\mathrm{A}$ and $\mathrm{B}(p>0.05)$. There were not enough observations to regress the data for region $\mathrm{C}$ independent of the other regions. TSM explained $73 \%$ of the variability in $b_{\mathrm{bp}}(550)$ across all three regions (Fig. 6). The highest TSM concentrations ( 3 to $12.5 \mathrm{mg} \mathrm{L}^{-1}$ ) and $b_{\mathrm{bp}}(550)$ coefficients $\left(0.9\right.$ to $\left.0.23 \mathrm{~m}^{-1}\right)$ were found in region $\mathrm{A}(p<0.05)$. Region A data were consistent with the overall relationship between TSM and $b_{\mathrm{bp}}(550)$ across all regions and helped establish a high TSM end member for the relationship. Although $b_{\mathrm{bp}}(550)$ values in region $\mathrm{B}$ were approximately half of those measured in region A, TSM also drove particulate backscattering in these locations (Fig. 6, $r^{2}=$ 0.61). Particulate backscattering and TSM values for region $\mathrm{C}$ were a fraction of those observed in region $\mathrm{A}$ and represented the low end member for the relationship between TSM and $b_{\mathrm{bp}}(550)$. 


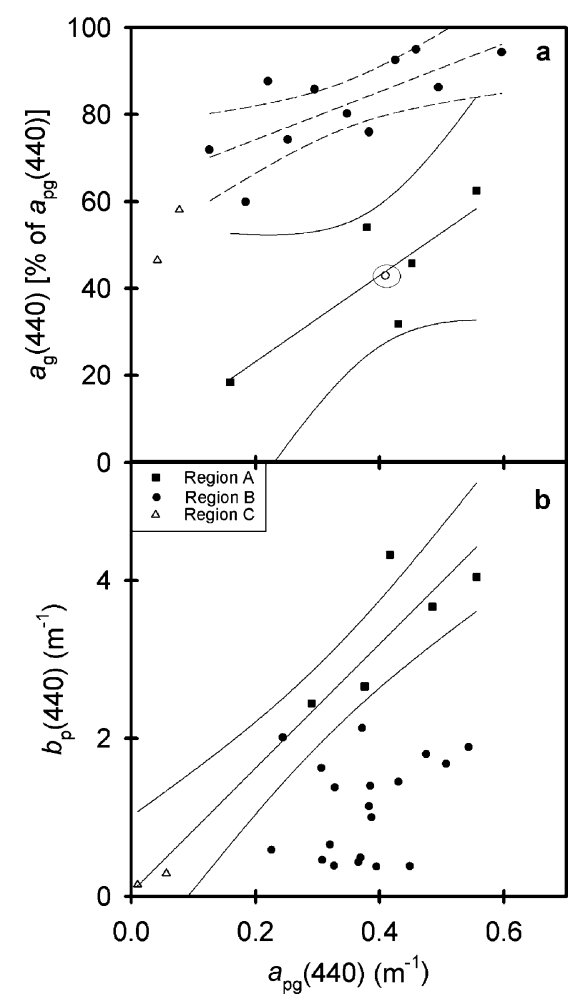

Fig. 3 a Percentage of absorption by dissolved matter $\left[a_{\mathrm{g}}(440)\right]$ plotted against $a_{\mathrm{pg}}(440)$. Linear regressions are plotted for region $\mathrm{A}$ $\left[a_{\mathrm{g}}(440)=99.0 a_{\mathrm{pg}}(440)+3.4 ; r^{2}=0.68 ; F=8.33 ; p<0.05\right]$ and region $\mathrm{B}\left[a_{\mathrm{g}}(440)=55.2 a_{\mathrm{pg}}(440)+63.2 ; r^{2}=0.53 ; F=6.45 ; p<0.05\right]$. The circled point represents an outlier and is not included in the regression for region B. b Scattering by particulate material at $440 \mathrm{~nm}$ plotted as a function of absorption by particulate and dissolved material at $440 \mathrm{~nm}$. Linear regression lines describe the relationship between regions $\mathrm{A}$ and $\mathrm{C}$ $\left[b_{\mathrm{b}}(440)=7.9 a_{\mathrm{pg}}(440)+0.53 ; r^{2}=0.92 ; F=59.57 ; p<0.05\right]$

Concentrations of TSM explained approximately $77 \%$ of the variation in total beam attenuation $\left[c_{\mathrm{pg}}(555)\right]$ (Fig. 7). Regions $\mathrm{A}$ and $\mathrm{C}$ represented the turbid and clear

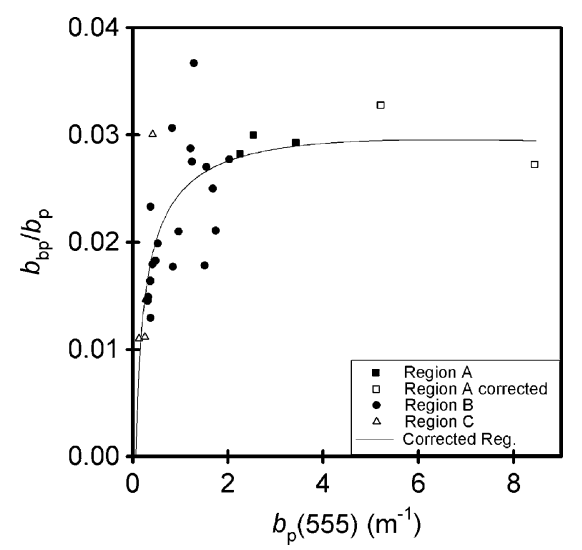

Fig. 4 The backscattering to scattering ratio $\left[b_{\mathrm{bp}}(550): b_{\mathrm{p}}(555)\right]$ plotted as a function of scattering $\left[b_{\mathrm{p}}(555)\right]$ at $555 \mathrm{~nm}$. The regression line describes the trend across all three regions $\left(\frac{b_{\text {bp }}}{b_{\mathrm{p}}}=0.025+0.0053 \times \ln \left(b_{\mathrm{p}}\right)-0.0014 \times\left[\ln \left(b_{\mathrm{p}}\right)\right]^{2} ; r^{2}=0.60 ;\right.$ $\left.F \stackrel{b_{\mathrm{p}}}{=} 19.09 ; p<0.05\right)$

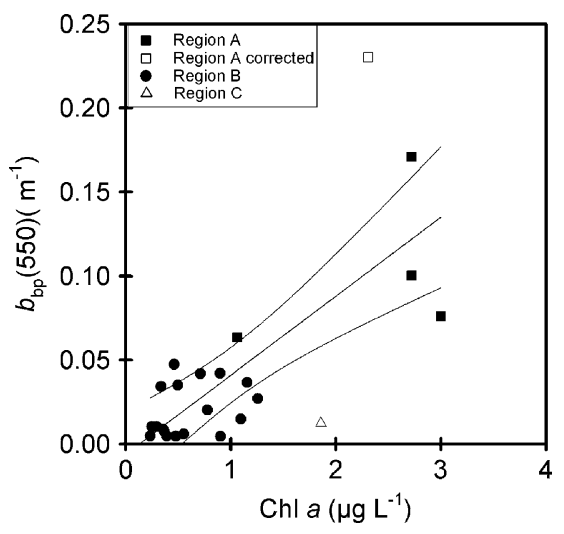

Fig. 5 Backscattering at $550 \mathrm{~nm}\left[b_{\mathrm{bp}}(550)\right]$ plotted against $\mathrm{Chl} a$ concentrations for regions $\mathrm{A}, \mathrm{B}$, and $\mathrm{C}$. A linear regression analysis was conducted across regions $\mathrm{A}$ and $\mathrm{B}\left(b_{\mathrm{bp}}=0.047 \mathrm{Chl} a-0.0061\right.$; $\left.r^{2}=0.53 ; F=35.8 ; p<0.05\right)$

end members of the study site. The majority of the particulate mass captured on the TSM filters for region B was acid labile $(\sim 92 \% \pm 14 \%)$ and likely consisting of inorganic carbonate particles resuspended from the seafloor. Furthermore, our data show that the ratio of backscattering to total attenuation $\left(b_{\mathrm{bp}} / c_{\mathrm{pg}}\right)$ was higher for region $\mathrm{A}$ (mean $=0.24 \pm 0.0008)$ than regions $\mathrm{B}$ $($ mean $=0.17 \pm 0.002)$ and $\mathrm{C}($ mean $=0.014 \pm 0.004)$. Visual observations of the milky green water column in region A also suggested a high carbonate load of resuspended sediment and were consistent with findings reported in Fig. 7.

Modeling Light-Limited Seagrass Density

Seagrass was found only at locations where the optical depth for blue light $\left[\zeta(\lambda)=K_{\mathrm{d}}(440) \cdot z\right]$ was $\leq 2.6$, corresponding to isolumes brighter than $7.5 \%$ of surface

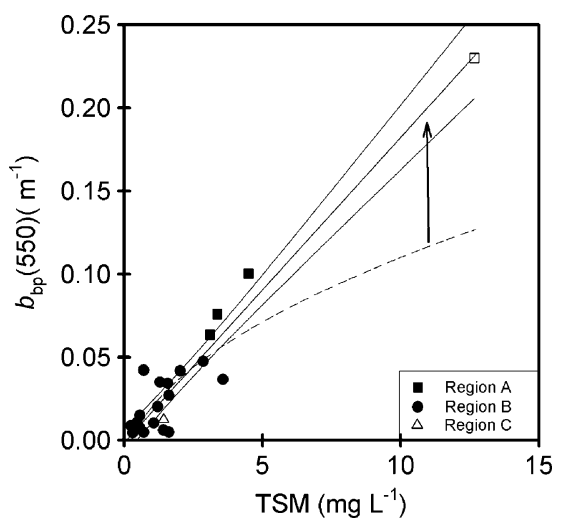

Fig. 6 TSM plotted against $b_{\mathrm{bp}}$ (550) for regions A, B, and C. A linear regression analysis was performed across all regions $\left(b_{\mathrm{bp}}=0.019 \mathrm{TSM}--0.002 ; r^{2}=0.73 ; F=53.23 ; p<0.05\right)$ as well as individually for region $\mathrm{B}\left(b_{\mathrm{bp}}=0.017 \mathrm{TSM}=0.002 ; r^{2}=0.61 ; p<\right.$ $0.05)$. The dashed and solid lines represent the regression lines from the uncorrected and corrected data, respectively 


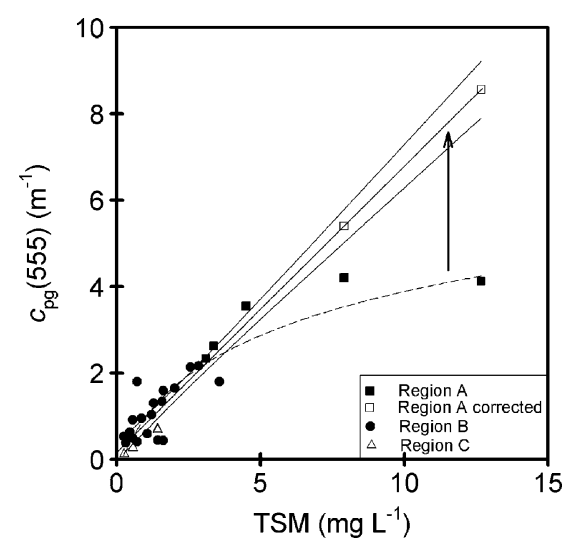

Fig. 7 Beam attenuation $\left[c_{\mathrm{pg}}(555)\right]$ plotted as a function of TSM. The solid line represents the linear regression of the corrected data $\left[c_{\mathrm{pg}}=0.66(\mathrm{TSM})+0.16 ; r^{2}=0.77 ; F=82.99 ; p<0.05\right]$. Oversaturated $c_{\text {pg }}(555)$ data were recalculated and plotted using the above linear regression equation that excluded oversaturated values

(in water) irradiance (Fig. 8a). Although this threshold conforms to the well-established depth limit for seagrass survival (Duarte 1991), field observations did not reveal a strong relationship between shoot density or LAI and optical depth (Fig. 8a). Instead, a wide variety of densities were found across the stations that met the $\zeta \leq 2.6$ criterion. The depth threshold for seagrass survival predicted by the two-flow radiative transfer model of Zimmerman (2003) was similar, but slightly lower (mean limit $=4.7 \%$ isolume; lower limit $=6.9 \%$ isolume; upper limit $=3.3 \%$ isolume) and a much stronger relationship between optical depth and maximum shoot density (Fig. 8b). However, the predicted light-limited shoot densities were up to $5 \times$ higher than those observed in the field, suggesting that several factors besides light may be regulating shoot densities with varying influences at specific locations.

The hypothetical amplification of CDOM and Chl $a$ absorption did not have strong influences on the modeled light-limited densities of seagrass. A minimum 5-fold increase in both CDOM and Chl $a$ would be required to increase $K_{\mathrm{d}}$ enough to reduce seagrass densities by $50 \%$ from their current levels in Greater Florida Bay. Thus, in the absence of major phytoplankton blooms or extensive release of riverine CDOM into the region, light scattering by suspended particles appears to be the most important optical factor controlling the light environment for seagrasses across Greater Florida Bay.

\section{Discussion}

Seagrass abundance and productivity are influenced by a variety of factors across Greater Florida Bay, including nutrients, salinity, and substrate type, but the relationship to light availability has often been ambiguous (Herbert and
Fourqurean 2009; Koch et al. 2007). Our study revealed a complex relationship between the inherent optical properties of the overlying water column and the distribution of seagrass across the region. The important role of non-algal particles and CDOM in determining the submarine light environment of this system is common to many estuaries and coastal regions (Gallegos 2001), and these materials can have significant impacts on the light-limited distribution of seagrasses (Zimmerman 2001).

We found three distinct environments based on coherent spatial patterns in IOPs, AOPs, and seagrass density. Region A, which was characterized by high scattering and high absorption, supported little to no seagrass. Our model calculations showed that the high attenuation coefficients, resulting primarily from scattering of resuspended carbonate sediments in this region, could explain the vanishingly low seagrass densities observed in this region. In contrast, the lower diffuse attenuation coefficients observed throughout region $\mathrm{B}$ permitted extensive, dense meadows of seagrass (mostly S. filiforme), although observed densities were lower than the light-limited predictions generated by

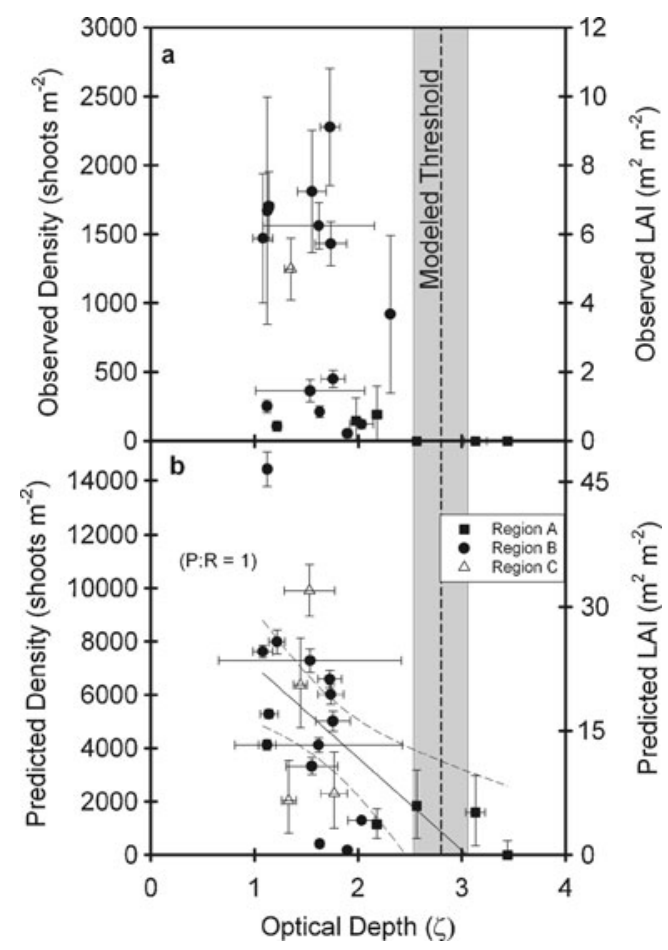

Fig. 8 a Observed shoot density and LAI $( \pm 95 \%$ confidence intervals) plotted as a function of optical depth $(\zeta ; \pm 95 \%$ confidence intervals) and regionally defined by symbol. b Predicted shoot densities ( $P: R=1 ; \pm 95 \%$ confidence intervals ) based on PUR input estimates using a two-flow bio-optical model and plotted as a function of optical depth $(\zeta ; \pm 95 \%$ confidence intervals). A linear regression analysis was performed across all regions (Density $=10,559-3,459 \zeta ; \quad r^{2}=0.35 ; \quad F=10.86 ; p<0.05$ ). The gray bar represents modeled thresholds (dashed line $=$ mean $\pm 95 \%$ confidence intervals) 
the radiative transfer model. In both regions $\mathrm{A}$ and $\mathrm{B}$, absorption was dominated by non-algal particles and CDOM. The oceanic region $\mathrm{C}$ supported patchy dense meadows of $T$. testudinum, but not $S$. filiforme. Model predictions for region $\mathrm{C}$ seagrass densities were similar in magnitude to region B. Agreement between model predictions and field observations of the optical depth threshold for seagrass survival indicates that light availability plays an important role in determining the depth limits of seagrass distribution in Greater Florida Bay. However, light does not appear to be controlling the density of seagrasses where they do exist. The lack of a statistically significant relationship between observed shoot density and optical depth, combined with model predictions of light-limited densities three to four times higher than observed in the field, indicates that other factors (e.g., nutrient availability; Fourqurean and Zieman 2002) limit shoot densities in locations where light is sufficient for seagrass meadows to persist. Previous work in Florida Bay identified the importance of nutrients, particularly phosphorus, in limiting seagrass density throughout Florida Bay (Fourqurean and Zieman 1992). Although seagrass populations did not approach lightlimited densities across region B of our study area, they were considerably higher, especially for $S$. filiforme, than on the much more oligotrophic Bahamas Banks, where $T$. testudinum is the most abundant seagrass and nutrient limitation is likely to be particularly strong (Burdige et al. 2008; Dierssen et al. 2003).

Seagrasses play a critical role in stabilizing unconsolidated sediments (Agawin and Duarte 2002). Consequently, previous seagrass losses may have led to the destabilization of sediments within Everglades National Park and resulted in a persistent turbid regime similar to conditions excluding seagrasses from region A. Tidal current velocities generally increase from the Keys (region B) towards Cape Sable (region A) where they often exceed $0.5 \mathrm{~ms}^{-1}$ (Wang 1998). In addition, persistent afternoon winds blowing across the shallow unvegetated region A may create Langmuir supercells capable of resuspending bottom sediments even in the absence of coherent tidal currents (Gargett and Wells 2007). In region A, strong tidal or wind-driven currents, seed burial, or grazing could destroy what little colonization occurs before a sufficient base population can be established (Dierssen et al. 2010; Koch et al. 2001). Similar mechanisms have been used to explain the failure of eelgrass to re-colonize former habitat in the Chesapeake Bay and Virginia coastal lagoons following widespread dieoffs from wasting disease in the 1930s (Carr et al. 2010; Orth et al. 2006).

High water column scattering in tandem with absorption was found in areas with little to no seagrass (region A). The high particulate backscattering ratios $\left(b_{\mathrm{bp}} / b_{\mathrm{p}} \geq 0.03\right)$, back- scattering to total attenuation ratio $\left(b_{\mathrm{bp}} / c_{\mathrm{pg}} \approx 0.23\right)$, and milky appearance of the water observed throughout region A were consistent with high concentrations of suspended mineral particles, rather than organic (algal or detrital) material (Boss et al. 2009; Twardowski et al. 2001). Further, the high acid lability of TSM captured on the filters indicated high concentrations of carbonates which most likely originated from resuspended benthic sediments and little influence by pigmented material. Additionally, our calculations show that the contribution of phytoplankton to TSM is not totally insignificant, but does not appear to be driving TSM across our study site. The relationship between Chl $a$ and TSM was linear $\left(r^{2}=0.42\right)$ with a slope of $0.42 \mu \mathrm{g} \mathrm{Chl} a / \mathrm{mg}$ TSM. Assuming carbon/Chl $a=50$, the relationship becomes $21 \mu \mathrm{g} \mathrm{C} / \mathrm{mg}$ TSM, and carbon represents $35 \%$ of the biomass of phytoplankton, then phytoplankton contributes $60 \mu \mathrm{g}$ mass/mg TSM or $\sim 6 \%$ $( \pm 3 \%)$ of TSM.

Similar to particulate material, CDOM absorbs strongly in the blue region of the spectrum and directly competes with the Soret absorption band of photosynthetic organisms, including seagrasses (Cummings and Zimmerman 2003). Although CDOM absorption was not high enough to have an appreciable impact on seagrass distributions in Greater Florida Bay, high concentrations of non-algal particulates and CDOM appear to be typical of the northwestern and central regions of Florida Bay (region A in this study), while the eastern region (including Everglades National Park) has been characterized by low algal and low particulate components (Boyer et al. 1999; Phlips et al. 1995). CDOM was not reported as a significant contributor to light attenuation in the Everglades National Park (Kelble et al. 2005). Historic decreases in freshwater delivery through the Everglades (Boesch et al. 1993) may be responsible for that condition. The relatively high concentrations of CDOM we observed in region $\mathrm{B}$ were unrelated to salinity, suggesting they are locally derived from seagrass, mangrove, aerobic decomposition of seagrass (Stabenau et al. 2004), and macroalgal decomposition (Zaneveld et al. 2001). Much of the local seagrass biomass is likely exported from Greater Florida Bay prior to decomposition because the leaves of $S$. filiforme, the most abundant species in region $\mathrm{B}$, retain their buoyancy for some time after abscission (Fry and Virnstein 1988). Conversely, the presence of shallow, isolated basins within Everglades National Park may reduce export of seagrasses, and their detritus is mostly likely a source of CDOM. The Comprehensive Everglades Restoration Plan to restore critical water flow to Florida Bay (Perry 2003) may result in greater concentrations of terrestrial derived $\mathrm{CDOM}$ delivered to Florida Bay in the future. In short, the biogeochemical source of CDOM in this system (terrestrial vs. marine, planktonic vs. benthic) remains an open 
question and specific estimates of marine vs. terrestrial fractions cannot be made at this time.

A variety of physical, chemical, and biological factors are clearly influencing seagrass growth and density in Florida Bay, as evidenced by differences between lightlimited densities predicted by our radiative transfer model and observed shoot densities. Although the proximate cause for the historic seagrass die-off in Florida Bay may never be fully resolved, it is interesting to note that the die-off was not preceded by significant decreases in growth of seagrass populations (Fourqurean and Robblee 1999). In fact, the high densities of apparently healthy plants may have been an initial response to system wide eutrophication. As seagrass populations approached light-limited densities, algal blooms and other insults may have initiated a cascade of events leading to the massive die-off, resulting in the destabilization of sediments and the present-day distribution of seagrasses in this ecosystem. Although the prevention of future eutrophication may be necessary for preserving large-scale ecosystem functions, including coral reefs and other habitats in Florida Bay, our field observations and model calculations indicate that nutrient control alone may be insufficient to enable the establishment of seagrass populations once optical properties are dominated by particulate scattering from resuspended sediments and that strict management of water quality must be established to prevent seagrass losses.

Acknowledgments Many thanks to D. Ruble, M. Stoughton, C. Buonassissi, A. Branco, J. Godfrey, D. Aurin, and J. Cousins for their assistance, persistence, and camaraderie in the field and lab. Financial support was provided by the Ocean Biology \& Biogeochemistry Program, NASA (project number: NNG04GN84G).

\section{References}

Agawin, N.S., and C.M. Duarte. 2002. Evidence of direct particle trapping by a tropical seagrass meadow. Estuaries 25: 1205-1209.

Boesch, D.F., N.E. Armstrong, C.F. D'Elia, N.G. Maynard, H.W. Pearl, and S.L. Williams. 1993. Deterioration of the Florida Bay ecosystem: An evaluation of the scientific evidence. West Palm Beach: National Fish and Wildlife Foundation, National Park Service, South Florida Water Management District.

Borum, J., O. Pedersen, T.M. Greve, T.A. Frankovich, J.C. Zieman, J.W. Fourqurean, and C.J. Madden. 2005. The potential role of plant oxygen and sulphide dynamics in die-off events of the tropical seagrass, Thalassia testudinum. Journal of Ecology 93: 148-158.

Boss, E., L. Taylor, S. Gilbert, K. Gundersen, N. Hawley, C. Janzen, T. Johengen, H. Purcell, C. Robertson, D.W.H. Schar, G.J. Smith, and M.N. Tamburri. 2009. Comparison of inherent optical properties as a surrogate for particulate matter concentration in coastal waters. Limnol. and Oceanogr. Methods 7: 803-810.

Boyer, J.N., J.W. Fourqurean, and R.D. Jones. 1999. Seasonal and long-term trends in the water quality of Florida Bay (19891997). Estuaries 22: 417-430.
Burdige, D.J., R.C. Zimmerman, and X. Hu. 2008. Rates of carbonate dissolution in permeable sediments estimated from pore-water profiles: The role of sea grasses. Limnology and Oceanography 53: $549-565$.

Butler, M., J.H. Hunt, W.F. Herrnkind, M.J. Childress, R. Bertelsen, W. Sharp, T. Matthews, J.M. Field, and H.G. Marshall. 1995. Cascading disturbances in Florida Bay, USA: Cyanobacteria blooms, sponge mortality, and implications for juvenile spiny lobsters Panulirus argus. Marine Ecology Progress Series 129: $119-125$.

Carlson, P.R., and K. Madley. 2007. Statewide summary for Florida. In Seagrass status and trends in the Northern Gulf of Mexico: 1940-2002, ed. L.L. Handley, D. Altsman, and R. DeMay, 99114. Reston: US Geological Survey.

Carr, J., P. D'Odorico, K. McGlathery, and P. Wiberg. 2010. Stability and bistability of seagrass ecosystem in shallow coastal lagoons: Role of feedbacks with sediment resuspension and light attenuation. Journal of Geophysical Research 115: 1-14.

Cummings, M.E., and R.C. Zimmerman. 2003. Light harvesting and the package effect in the seagrasses Thalassia testudinum Banks ex Konig and Zostera marina L.: Optical constraints on photoacclimation. Aquatic Botany 75: 261-274.

Dierssen, H.M., R.C. Zimmerman, R.A. Leathers, T.V. Downes, and C.O. Davis. 2003. Ocean color remote sensing of seagrass and bathymetry in the Bahamas high-resolution airborne imagery. Limnology and Oceanography 48: 444-455.

Dierssen, H.M., R.C. Zimmerman, D.J. Burdige, and L. Drake. 2010. Benthic ecology from space: Optics and net primary production cross the Great Bahama Bank from seagrass to benthic algae. Marine Ecology Progress Series 411: 1-15.

Duarte, C.M. 1991. Seagrass depth limits. Aquatic Botany 40: 363-377.

Durako, M.J., J.C. Zieman, and M. Robblee. 2007. Seagrass ecology. In Florida Bay science program: A synthesis of research on Florida Bay, ed. J. Hunt and W. Nuttle, 92-100. St. Petersburg: Florida Fish and Wildlife Conservation Commission, Fish and Wildlife Research Institute.

Fourqurean, J.W. 2008. Seagrass monitoring in the Florida keys national marine sanctuary. Miami: Florida International University, Southeast Environmental Research Center and Department of Biology.

Fourqurean, J., and M. Robblee. 1999. Florida Bay: A history of recent ecological changes. Estuaries 22: 345-357.

Fourqurean, J.W., and J.C. Zieman. 1992. Phosphorus limitation of primary production in Florida Bay: Evidence from $\mathrm{C}: \mathrm{N}: \mathrm{P}$ ratios of the dominant seagrass Thalassia testudinum. Limnology and Oceanography 37: 162-171.

Fourqurean, J.W., and J.C. Zieman. 2002. Nutrient content of the seagrass Thalassia testudinum reveals regional patterns of relative availability of nitrogen and phosphorus in the Florida Keys USA. Biogeochemistry 61: 229-245.

Fourqurean, J.W., A. Willsie, C.D. Rose, and L.M. Rutten. 2001. Spatial and temporal pattern in seagrass community composition and productivity in south Florida. Marine Biology 138: $341-354$.

Fourqurean, J.W., J.N. Boyer, M.J. Durako, L.N. Hefty, and B.J. Peterson. 2003. Forecasting responses of seagrass distributions to changing water quality using monitoring data. Ecological Applications 13: 474-489.

Fry, B., and R.W. Virnstein. 1988. Leaf production and export of the seagrass Syringodium filiforme Kütz. in the Indian River Lagoon, Florida. Aquatic Botany 30: 261-266.

Gallegos, C. 2001. Calculating optical water quality targets to restore and protect submersed aquatic vegetation: Overcoming problems in partitioning the diffuse attenuation coefficient for photosynthetically active radiation. Estuaries 24: 381-397. 
Gargett, A., and J. Wells. 2007. Langmuir turbulence in shallow water. Part I. Observations. Journal of Fluid Mechanics 576: 27-61.

Gould Jr., R.W., R.A. Arnone, and P.M. Martinolich. 1999. Spectral dependence of the scattering coefficient in case 1 and case 2 waters. Applied Optics 38: 2377-2383.

Hall, M., M. Durako, J. Fourqurean, and J. Zieman. 1999. Decadal changes in seagrass distribution and abundance in Florida Bay. Estuaries 22: 445-459.

Herbert, D.A., and J.W. Fourqurean. 2009. Phosphorus availability and salinity control productivity and demography of the seagrass Thalassia testudinum in Florida Bay. Estuaries and Coasts 32: 188-201.

Hojerslev, N. 1975. A spectral light absorption meter for measurements in the sea. Limnology and Oceanography 20: 1024-1034.

Kelble, C., P. Ortner, G. Hitchcock, and J. Boyer. 2005. Attenuation of photosynthetically available radiation (PAR) in Florida Bay: Potential for light limitation of primary producers. Estuaries 28: 560-571.

Kirk, J.T. 1994. Light and photosynthesis in aquatic ecosystems, 2nd ed. New York: Cambridge University Press.

Koch, M.S., R.E. Benz, and D.T. Rudnick. 2001. Solid-phase phosphorus pools in highly organic carbonate sediments of northeastern Florida Bay. Estuarine, Coastal and Shelf Science 52: 279-291.

Koch, M.S., S.A. Schopmeyer, O.I. Nielsen, C. Kyhn-Hansen, and C. J. Madden. 2007. Conceptual model of seagrass die-off in Florida Bay: Links to biogeochemical processes. Journal of Experimental Marine Biology and Ecology 350: 73-88.

Mitchell, B.G., M. Kahru, J. Wieland, and M. Stramska. 2002. Determination of spectral absorption of particles, dissolved materials and phytoplankton for discrete water sample. In Ocean optics protocols for satellite ocean color sensor validation, ed. J. Mueller and L.G.S. Fargion, 231-257. Hanover: NASA.

Mobley, C.D. 1989. A numerical model for the computation of radiance distributions in natural waters with wind-roughened surfaces. Limnology and Oceanography 34: 1473-1483.

Mobley, C.D. 1994. Light and water: Radiative transfer in natural waters, 1st ed. New York: Academic.

Morel, A. 1978. Available, usable, and stored radiant energy in relation to marine photosynthesis. Deep-Sea Research 25: 673-688.

Morel, A., and L. Prieur. 1977. Analysis of variations in ocean color. Limnology and Oceanography 22: 709-722.

Orth, R.J., M.L. Luckenbach, S.R. Marion, K.A. Moore, and D.J. Wilcox. 2006. Seagrass recovery in the Delmarva Coastal Bays, USA. Aquatic Botany 84: 26-36.

Perry, W. 2003. Elements of South Florida's comprehensive everglades restoration plan. Ecotoxicology 13: 185-193.

Phlips, E.J., T.C. Lynch, and S. Badylak. 1995. Chlorophyll $a$, tripton, color, and light availability in a shallow tropical inner-shelf lagoon, Florida Bay, USA. Marine Ecology Progress Series 127: 223-234.

Pope, R.M., and E.S. Fry. 1997. Absorption spectrum (380-700 nm) of pure water. II. Integrating cavity measurements. Applied Optics 36: 8710-8723.

Prieur, L., and S. Sathyendranath. 1981. An optical classification of coastal and oceanic waters based on the specific spectral absorption curves of phytoplankton pigments, dissolved organic matter, and other particulate materials. Limnology and Oceanography 26: 671689.

Ralph, P.J., M.J. Durako, S. Enríquez, C.J. Collier, and M.A. Doblin. 2007. Impact of light limitation on seagrasses. Journal of Experimental Marine Biology and Ecology 350: 176-193.

Sargent, F.J., T.J. Leary, D.W. Crewz, and C.R. Druer. 1995. Scarring of Florida's seagrasses: Assessment and management options. St. Petersburg: Florida Marine Research Institute.

Stabenau, E.R., R.G. Zepp, E. Bartels, and R.G. Zika. 2004. Role of the seagrass Thalassia testudinum as a source of chromophoric dissolved organic matter in coastal south Florida. Marine Ecology Progress Series 282: 59-72.

Stoughton, M. 2008. A bio-optical model for Syringodium filiforme. Thesis. Norfolk: Old Dominion University.

Stumpf, R.P., M.L. Frayer, M.J. Durako, and J.C. Brock. 1999. Variations in water clarity and bottom albedo in Florida Bay from 1985 to 1997 . Estuaries 22: 431-444.

Twardowski, M.S., E. Boss, W. Macdonald, S. Pegau, A.H. Barnard, and R.V. Zaneveld. 2001. A model for estimating bulk refractive index from the optical backscattering ratio and the implications for understanding particle composition in case I and case II waters. Journal of Geophysical Research, Oceans 105: $14129-14142$.

US Fish and Wildlife Service. 1999. South Florida multi-species recovery plan. Atlanta: D. o. Interior.

Wang, J.D. 1998. Subtidal flow patterns in western Florida Bay. Estuarine, Coastal and Shelf Science 46: 901-915.

WET Labs, I. 2009. ac Meter Protocol Document. Philomath: WET Labs. 53.

Zaneveld, J.R., E. Boss, and C.M. Moore. 2001. A diver-operated optical and physical profiling system. Journal of Atmospheric and Oceanic Technology 18: 1421-1427.

Zieman, J.C. 1982. The ecology of the seagrasses of South Florida: A community profile, 158. Washington, DC: US Fish and Wildlife Services.

Zieman, J.C., J.W. Fourqurean, and R.L. Iverson. 1989. Distribution, abundance, and productivity of seagrasses and macroalgae in Florida Bay. Bulletin of Marine Science 44: 292-311.

Zimmerman, R.C. 2001. Appendix M. Final report: A bio-physical model evaluation of eelgrass distribution and habitat potential in Dumas Bay, WA. In Puget sound submerged vegetationmonitoring project: 2000-2003 monitoring report, ed. H.D. Berry, A.T. Sewell, S. Wyllie-Echeverria, B.R. Reeves, T.F. Mumford Jr., J.R. Skalski, R.C. Zimmerman, and J. Archer, M1-M25. Olympia: Nearshore Habitat Program, Aquatic Resources Division, Washington State Department of Natural Resources.

Zimmerman, R.C. 2003. A biooptical model of irradiance distribution and photosynthesis in seagrass canopies. Limnology and Oceanography 48: 568-585.

Zimmerman, R.C. 2006. Chapter 13. Light and photosynthesis in seagrass meadows. In Seagrass: Biology, ecology and conservation, ed. A.W.D. Larkum, R.J. Orth, and C.M. Duarte, 303-321. Dordrecht: Springer. 